\title{
Assessment of Oxytetracycline Residue in Table Eggs from Khartoum State's Markets
}

\author{
Sara A M ${ }^{1 *}$, Hala A E ${ }^{1}$, Sahar M N, Samia A A Hassan ${ }^{1}$, Inaam EL A Dawd ${ }^{1}$, Hadeel A AMabyie ${ }^{1}$, \\ Samia H Abdulrahman ${ }^{1}$ and Iahraga G $\mathbf{I}^{1}$ \\ ${ }^{1}$ Central Veterinary Research Laboratory, Khartoum-Sudan
}

*Corresponding author: Sara A M, Central Veterinary Research Laboratory, Khartoum-Sudan.

To Cite This Article: Sara A M, Hala A E, Sahar M N, Samia A A Hassan, Inaam EL A Dawd, et al., Assessment of Oxytetracycline Residue in Table Eggs from Khartoum State's Markets. Am J Biomed Sci \& Res. 2021 - 14(1). AJBSR.MS.ID.001941. DOI: 10.34297/AJBSR.2021.14.001941.

Received: 眥 August 03, 2021; Published: 眥 August 25, 2021

\begin{abstract}
Background: Antibiotics residue in food from animal origin represents a public health issue concerns the authorities worldwide.

Method: 100 egg samples were collected from Khartoum state's markets to evaluate the current situation of oxy tetracycline residue. briefly, Samples were homogenized, weighed ( $2 \mathrm{~g}$ ); and processed by adding citric acid ( $100 \mathrm{mg}), 30 \%$ nitric acid ( $1 \mathrm{ml})$, methanol (4 ml) followed by adding $1 \mathrm{ml}$ of deionized water; then centrifuged at 5300 for 10 mints followed by filtration throughout $0.22 \mu \mathrm{m}$ syringe filter and $20 \mu \mathrm{l}$ of the sample was injected into HPLC equipped with UV-VIS detector and ODS (C-18) column and read at $360 \mathrm{~nm}$.

Result: $49 \%$ of total samples were positive. $48 \%$ of those positive samples (24 out of 49); were equal or exceeded the MRL of Oxytetracycline in egg $(200 \mathrm{ppb})$. The mean values obtained from the three different state's cities were not significantly different between different localities, nevertheless between each city and the MRL the variance was vastly significant.
\end{abstract}

Keywords: HPLC; Oxytetracycline; Egg; MRL

Abbreviations: HPLC: High Performance Liquid Chromatography; MRL: Maximum Residue Limit; LLE: Liquid-Liquid Extraction; Ppb: Part Per Billion; OCT: Oxytetracycline; LOD: Limit of Detection; LOQ: Limit of Quantitation

\section{Introduction}

Fowls are tended for meat and egg production as a vital protein sources. Drugs are crucial section of chicken production and used to preclude and manage diseases, reduce stress due to environmental alterations, vaccination and other administration practices. Antibiotics are described as the antimicrobial substances that are produced both naturally by residing organisms or synthetically by way of laboratory processes with the potential to inhibit the boom of microorganisms or kill the microorganisms [1]. Antibiotics are industrially produced for the cause of the prevention and therapy of animal ailments such as mastitis, brucellosis, gastrointestinal diseases, respiratory diseases and many other bacterial infectious ailments [2].

In intensified farming antibiotics are also used to advance animal production like amplify of growth level and increasing weight gain [3]. When these antibiotics are administered to an animal, they dissolve and distribute rapidly in animal tissues and fluids. Over $90 \%$ of these antibiotics bind to plasma proteins and attain a high concentration between the 3rd and sixth hour of administration [4], they are then metabolized in the liver and are expelled through glomerular filtration. If the right technique is no longer used in administration and use of these pills, they are left in large amounts i.e., residues, in animal products like milk and egg [5]. The occurrence of antibacterial drug residues in eggs can carriage a health hazard to consumers such as hypersensitivity reaction, development of resistant organisms to these antibacterial agents and damage of gastrointestinal natural microbiota [6].

Depending on the type of antimicrobial administrated to the animal, variable periods of time is needed to avoid the tremendous harmful effect of the parent administrated drug or it's metabolites residue on the consumer's health, [7]. Direct impact on customers 
may be witnessed, such as allergy in hypersensitive persons [8] Residue may also be the underlying reason behind the initiation of resistant strains of bacteria. Thus, assurance on presence of regulations govern the exist of antimicrobial residue in food; has become a necessity. Oxytetracycline (OTC) is currently accredited for use in feed to amplify egg manufacturing and feed competence and for the prevention of ailment for breeder hens and meat-type chicken [9]. Oxytetracycline is now not authorized for use in laying hens producing eggs for human consumption. However, eggs may incorporate OTC residues after:

i. Illegal or extra-label use of drugs

ii. Use of feed unintentionally cross contaminated during feed mixing

iii. Use of mislabeled broiler feed in laying hens

Presently, there's no obligatory protocols or laws to control the usage of antimicrobial. Evermore there are no authorized structures to guarantee that food from animal origin is subjected to observation and obligation by the permitted level of antimicrobial. Thus, the current study done to screen the existence of oxytetracycline in table eggs, that collected from various areas of Khartoum state, and to figure out whether the level of residue is acceptable referring to the MRLs, which established the global concerned authorities.

\section{Materials and Methods}

\section{Chemicals and Standard}

Nitric acid 69\%, Methanol HPLC grade, Acetonitrile HPLC grade, Citric acid and Sulfuric acid were purchased from Sigma Aldrich and HPLC pure water.

Oxytetracycline hydrated reference standard was attained from Sigma Aldrich.

\section{Equipment}

HPLC (SYKAM), Centrifuge (Hitachi, Germany) and Ultrasonic water bath (Elma, Germany).

\section{Samples Collection and Process}

egg samples were assembled randomly from different Khartoum state's markets, the number of whole samples was 100, distributed respectively as 16 samples from Bahri, the same number was collected from Omdurman, while Khartoum capital represented by 68 samples. Carton and plastic plates were used to bring samples to the central veterinary research laboratories. Samples proceeded as

\section{Results and Discussion}

Table 1: Method validation values. soon as reached the lab. At room temperature $\left(25-30_{0} \mathrm{C}\right)$, sample's surface cleaned out by alcohol, punctured and the whole egg transferred into plastic containers. Samples homogenized gently and deeply freezed at $-20_{0} \mathrm{C}$ until analysis.

\section{Sample Preparation}

Following the method described by [10], samples were extracted (LLE). Tow grams of well homogenized egg sample were taken into falcon tube, $100 \mathrm{mg}$ of citric acid, $1 \mathrm{ml}$ of (30\%) nitric acid, $4 \mathrm{ml}$ of methanol and $1 \mathrm{ml}$ of deionized water were added to the samples in order. Samples were vortexed and placed in ultrasonic water bath for $15 \mathrm{~min}$, followed by centrifugation at $5300 \mathrm{rpm}$ for $10 \mathrm{mints}$. sample supernatant was filtered through $0.22 \mu \mathrm{m}$ syringe filter and $20 \mu \mathrm{l}$ of the filtrate was introduced to the HPLC for analysis.

\section{Standard Solution Preparation}

Stock solution: $0.001 \mathrm{~g}$ of oxy tetracycline hydrate was dissolved in $10 \mathrm{ml}$ absolute methanol to give concentration 1000 ppb. Five serial dilutions were prepared from the stock solution $(100,200,300,400$ and $500 \mathrm{ppb})$.

Mobile phase: The mobile phase made up of deionized water (A); $(\mathrm{PH}=2.1)$, and acetonitrile (B) with ratio 85:15 respectively.

Analysis condition: Samples were injected in HPLC (Sykam), coupled with UV-VIS detector. ODS-3 (C-18) column, S1122 quaternary pump with flow adjusted at $1 \mathrm{ml} / \mathrm{min}$, oxytetracycline detected at wavelength $360 \mathrm{~nm}$. The calibration curve of different standards was used to convert samples peak area to concentration.

Method validation: The HPLC assay linearity was determined by analysis of series standard solution on three different days in concentrations ranged between 100-500 $\mu \mathrm{g} / \mathrm{ml}$. the Calibration curve plotted using the linear least squares regression procedure of the peak area ratios against concentrations.

Extraction recovery: Spiked samples were prepared by adding $100 \mu \mathrm{l}$ of $(300,400$ and $500 \mathrm{ppb})$, standard solutions to blank sample. Spiked samples were fortified on 3 different days. The average of recovery values was used to evaluate the residue concentration and the precision of data.

LOD and LOQ determination: Limit of detection and limit of quantitation, were evaluated by calculating the value of slope and the standard deviation of the samples read, using the equation LOD $=3.3($ STD $/ S L O P E)$.

$\mathrm{LOQ}=10(\mathrm{STD} / \mathrm{SLOPE})$, these limits were determined by inducing three points calibration curve made with spiked samples.

\begin{tabular}{|c|c|c|c|c|}
\hline LOD PPb & LOQ PPb & $\mathbf{R}^{\mathbf{2}}$ & RECOVERY\% & MRL PPb \\
\hline 12 & 36 & 0.996 & 87 & 200 \\
\hline
\end{tabular}


Table 2: Distribution of positive samples from different Khartoum state's cities.

\begin{tabular}{|c|c|c|c|c|}
\hline City & Number of positive samples & $\begin{array}{c}\text { Percentage of total } \\
\text { (\%) }\end{array}$ & $\begin{array}{c}\text { Number of sample equal or } \\
\text { exceeded MRL }\end{array}$ & $\begin{array}{c}\text { Percentage of positive } \\
\text { (\%) }\end{array}$ \\
\hline Khartoum & 34 & 70 & 16 & 47 \\
\hline Bahri & 8 & 16 & 5 & 62 \\
\hline Omdurman & 7 & 14 & 3 & 42 \\
\hline
\end{tabular}

Figure 1: Oxytetracycline structure.

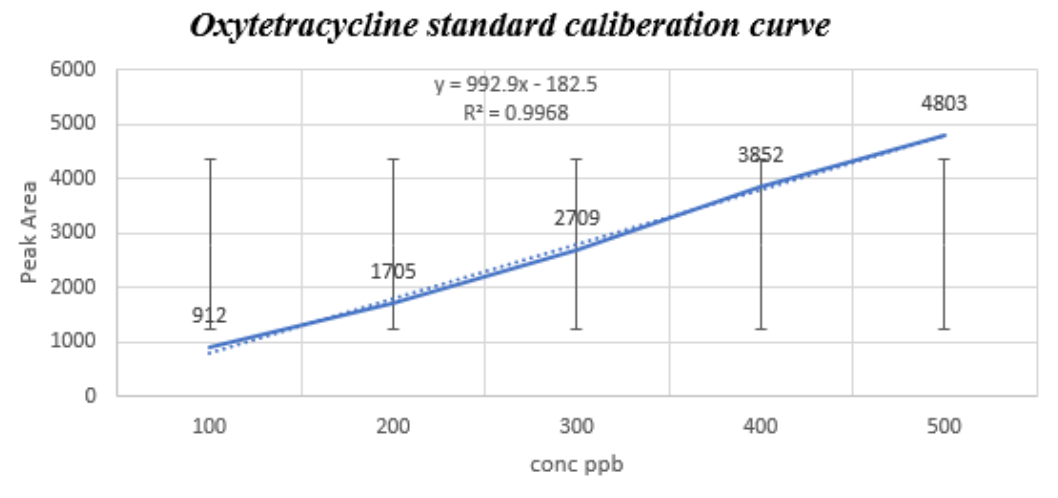

Figure 2: Standard calibration curve.

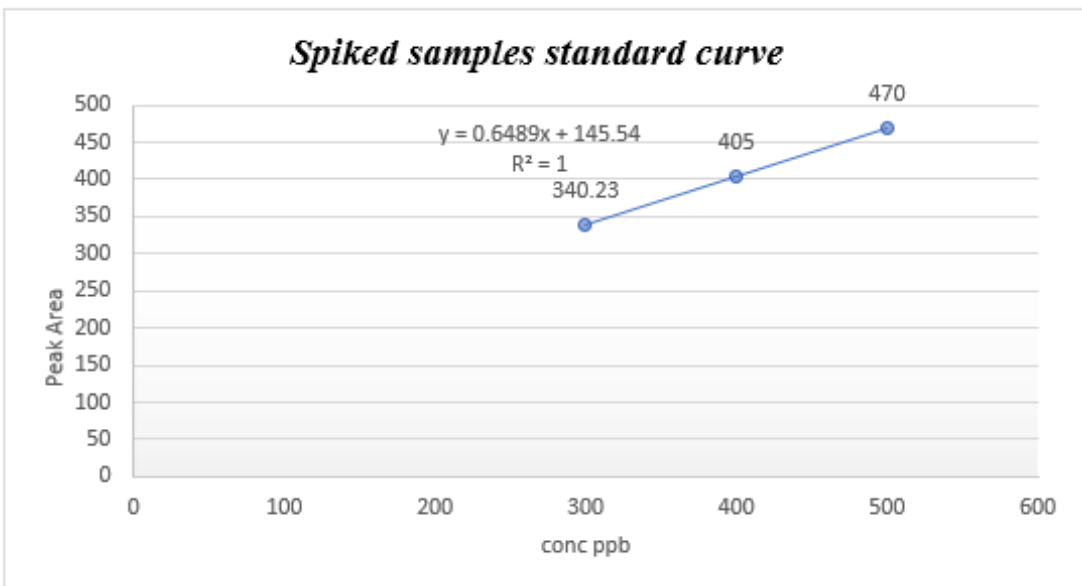

Figure 3: Spiked samples calibration curve. 


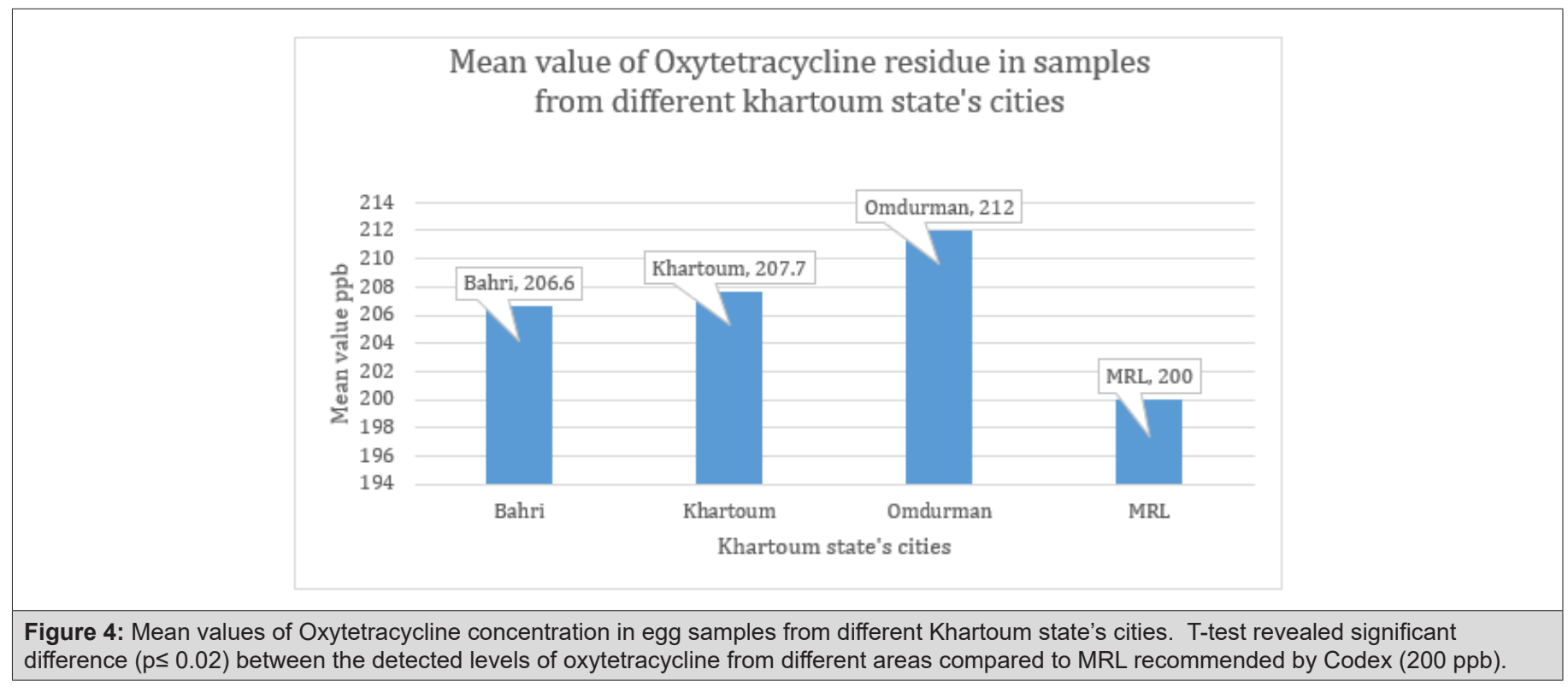
difference $(p \leq 0.02)$ between the detected levels of oxytetracycline from different areas compared to MRL recommended by Codex $(200$ ppb).

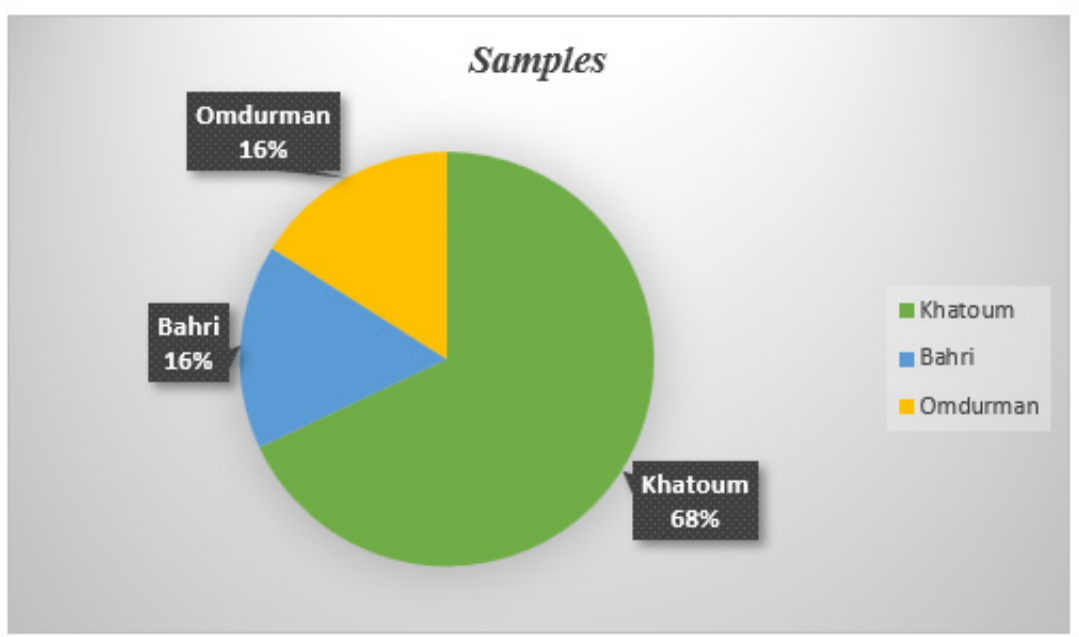

Figure 5: Distribution (\%) of total collected samples.

Total investigated samples are 100 (Figure 4). positive samples represented $49 \%$ of total number of tested ones, distributed between different state areas. Khartoum locality emanated first with 34 positive samples (70\%), followed by Bahri which recorded 8 positive samples (16\%). Omdurman municipal; came at the third position with the lowest number of positive samples (7); symbolize $14 \%$ of total positive samples, (Table 2).

Regarding the levels of detected OCT residue in positive samples compared to the MRL determined by Codex (200 ppb); $47 \%$ of Khartoum positive samples recorded residue concentration equal or exceeds the MRL. $62 \%$ and $42 \%$ of positive samples from Bhri and Omdurman, respectively were equal or beyond the MRL. The difference of various levels detected in samples from different areas was no significant statistically, while using T-test to compare different detected values of oxytetracycline in comparison with the maximum residue limit defined by [11], revealed highly significant difference $(\mathrm{p} \leq 0.02)$.

According to prevailing statistics. The incidence of antimicrobial residue; in egg samples in Africa and third world as general, represents a huge percentage. The findings of the current study do not much vary from results published from previous studies, despite the difference in methods used for analysis. Salehzadeh et al. [12], conducted study at Tehran; to assess the residue of OCT residue in samples gathered from 86 farm, the obtained result revealed that $95 \%$ of the farms recorded residue above the permissible level. The occurrence of antimicrobial was studied by [13]; in egg samples from Trinidad, results showed $16.1 \%$ in eggs collected from malls and $15 \%$ in samples collected from supermarkets. A study carried out by [14], to evaluate the residue of antimicrobial in table eggs in Tanzania, showed that all collected samples (70); were positive for 
antibacterial, the analysis was done using Delvotest kit. Algamidi [15], documented the existence of OCT in egg samples assembled from different regions of Saudi Arabia using HPLC method.

A study performed by, Sirdar [16], to evaluate the residue of antibiotics residue in commercial egg from Khartoum state farms; in period between 2007-2008, he stated there is a strong association between reported poultry diseases and the presence antibiotics residue in egg samples collected from commercial farms when samples screened using antimicrobial inhibition test. Hind [17], conducted study to monitor the residue of OCT in egg samples gathered from Khartoum State-Sudan. HPLC analysis of collect samples resulted in 35\% samples above the allowed limit.

\section{Conclusion}

The present and previous studies result in Khartoum state, ensures the need for firm law applied by specialized structure to govern the use of antimicrobial in poultry sector. This structure follows up the usage of antimicrobial and commitment of farms owners with withdrawal period of every drug. Following vaccination program and restricted hygiene system may lower the need to use antimicrobial drugs consequently avoid the risk of residual parent drug or it's metabolites in poultry products. The current comprehensive concern of antimicrobial resistant issue, which raised from the random use of antimicrobial requires official and civilian collaboration to guarantee safe poultry products free of residue served for the consumers.

\section{References}

1. Wageh SD, Elsaid AE, Mohamed TE, Yoshinori I, Shouta N, et al. (2013) Antibiotic residues in Food: The African Scenario. Jpn J Vet Res 61(Supplement):13-22.

2. Tollefson L, Miller M (2000) Antibiotic use in food animals: controlling the human health impact. J AOAC Int 83(2): 245-254.

3. Joy Deborah Orwa, Joseph Wafula Matofari, Patrick Simiyu Muliro, Peter Lamuka (2017) Assessment of sulphonamides and tetracyclines antibiotic residue contaminants in rural and peri urban dairy value chains in Kenya. J Food Contamination 4: 5.

4. Sulejmani Z, Shehi A, Hajrulai Z, Mata E (2012) Abuse of Pharmaceutical Drugsantibiotics in Dairy Cattle in Kosovo and Detection of their Residues in Milk. J Ecosyst Ecogr 2(19):114-120.
5. Richelle RG (2007) Investigation of Safe-Level Testing for Beta-lactam, Sulfonamide, and Tetracycline Residues in Commingled Bovine Milk. USA: Doctoral thesis, Salve Regina University.

6. Ehsani A, Hashemi M (2015) Determination of Antibacterial Drug Residues in Commercial Eggs Distributed in Urmia, Iran. J Food Quality \& Hazards Control 2: 61-65.

7. Dayan A.D (1993) Allergy to antimicrobial residues in food: assessment of the risk to man. Vet Microbiol 35:213-226.

8. Stolker A A, Brinkman U A (2005) Analytical strategies for residue analysis of veterinary drugs and growth-promoting agents in foodproducing animals--a review. J Chromatogr A 1067(1-2):15-53.

9. Code of Federal Regulation 21CFR 556.500 (1998) The Office of the Federal Register National Archives and Records Administration, Washington, USA.

10. Senyuva H, Ozden T, Sarica DY (2000) Highperformance liquid chromatographic determination of oxytetracycline residue in cured meat products. Instrumental Analysis Center, Scientific and Technical Research Council of Turkey (TUBITAK) 06530, Ankara-Turkey. Turk. J. Chem 24: 395-400.

11. Codex Alimentarius Commission (2012) Maximum residue limits for veterinary drugs in foods. Updated as at the $35^{\text {th }}$ session of the Codex Alimentarius Commission. CAC/MRL 2-2012: 1-40.

12. Salehzadeh F, Madani R, Salehzadeh A, Rokni N, Golchinefar F (2006) Oxytetracycline residue in chicken tissues from Tehran slaughterhouses in Iran. Pakistan Journal of Nutrition 5(4): 377-381.

13. Adestyun A, Offiah N, Lsahley V, Seepersadsingh N, Rodrigo S, et al. (2005) Prevalence of antimicrobial residues in table eggs in Trinidad. J Food Prot 68(7): 1501-1505.

14. H E Nonga, C Simon, E D Karimuribo, R H Mdegela (2010) Assessment of antimicrobial usage and residues in commercial chicken eggs from small holder poultry keepers in Morogoro Municipality, Tanzania. Zoonoses Public health 57(5): 339-344.

15. M S Al-Ghamdi, Z H Al Mustafa, F El Morsy, A Al Faky, I Haider, et al. (2000) Residues of tetracycline compounds in poultry products in the eastern province of Saudi Arabia. Public Health 114(4): 300-304.

16. Mohamed M Sirdar, Jackie Picard, Shahn Bisschop, Alexander R Jambalang, Bruce Gummow (2012) Survey of antimicrobial residues in table eggs in Khartoum State, Sudan, 2007-2008'. Onderstepoort J Vet Res 79(1):1-9.

17. Hind E A, Osman K M, Ishraga, G Ibrahim, Sabiel Y A (2018) Detection of Oxytetracycline Residues in Table Eggs in Khartoum State, Sudan. European Journal of Nutrition \& Food Safety 8(4): 148-154. 